\title{
Excess mortality and morbidity during the July 2006 heat wave in Porto, Portugal
}

\author{
Ana Monteiro • Vânia Carvalho • Teresa Oliveira • \\ Carlos Sousa
}

Received: 4 May 2011 /Revised: 23 November 2011 / Accepted: 26 March 2012 /Published online: 1 May 2012

(C) ISB 2012

\begin{abstract}
The purpose of this study was to understand the effects of the July 2006 heat wave through the use of the heat index, in mortality (all causes) and morbidity (all causes, respiratory and circulatory diseases) in general, and in people over 74 years and by gender, in Porto. In this paper, the Poisson generalized additive regression model was used to estimate the impact of apparent temperature (heat index) and daily mortality and morbidity during the July 2006 heat wave. Daily mortality, morbidity and heat index were correlated with lags of apparent temperature up to 7 days using Pearson correlation. For a $1{ }^{\circ} \mathrm{C}$ increase in mean apparent temperature we observed a $2.7 \%(95 \% \mathrm{CI}$ : $1.7-3.6 \%$ ) increase in mortality (all cause), a $1.7 \%$ (95\% CI: $0.6-2.9 \%$ ) increase in respiratory morbidity, a $2.2 \%$ (95\% CI: $0.4-4.1 \%$ ) increase in respiratory morbidity in women, a $5.4 \%(95 \% \mathrm{CI}: 1.1-6.6 \%)$ increase in chronic obstructive pulmonary morbidity, and a $7.5 \%(95 \% \mathrm{CI}$ : $1.3-14.1 \%$ ) increase in chronic obstructive pulmonary
\end{abstract}

\footnotetext{
A. Monteiro $\cdot$ T. Oliveira $\cdot$ C. Sousa

Department of Geography, Public Health Institute,

Porto University,

CITTA, Via Panorâmica $\mathrm{s} / \mathrm{n}^{\circ}$,

4150-564 Porto, Portugal

A. Monteiro

e-mail: anamonteirosousa@gmail.com

T. Oliveira

e-mail: teresa.rosas.oliveira@gmail.com

C. Sousa

e-mail: miguelsousa83@gmail.com

V. Carvalho $(\bowtie)$

FMUP, Public Health Institute, Porto University,

CITTA, Via Panorâmica $s / n^{\circ}$,

4150-564 Porto, Portugal

e-mail: carvalho.vania@gmail.com
}

morbidity in women, for the entire population. For people $\geq 75$ years, our results showed a $3.3 \%$ increase $(95 \%$ CI: $1.7-5.0 \%)$ in respiratory morbidity, a $2.7 \%(95 \% \mathrm{CI}$ : $0.4-5.1 \%$ ) increase in respiratory morbidity in men, a $3.9 \%$ (95 \% CI: $1.6-6.3 \%)$ increase in respiratory morbidity in women, a $7.0 \%$ (95 \% CI: 1.1-13.2\%) in chronic obstructive pulmonary disease, and a $9.0 \%$ (95\% CI: $0.3-18.5 \%)$ in chronic obstructive pulmonary disease in women. The use of heat index in a Mediterranean tempered climate enabled the identification of the effects of the July 2006 heat wave in mortality due to all causes and in respiratory morbidity of the general population, as well as in respiratory morbidity of individuals with more than 74 years of age.

Keywords Heat wave $\cdot$ Heat index $\cdot$ Mortality $\cdot$ Respiratory disease $\cdot$ Circulatory disease $\cdot$ Air pollution

\section{Introduction}

Climate change projections for the twenty-first century point towards an increase in the frequency, duration and intensity of heat waves (Planton et al. 2008; Gosling et al. 2009; Ballester et al. 2010) for Europe, particularly in Mediterranean European regions (Dessai 2002, 2003; Díaz et al. 2002a, b, 2006; Meehl and Tebaldi 2004).

The high number of deaths and hospital admissions resulting from the heat waves that have affected Europe (Calado et al. 2004; D'lppoliti et al. 2010; Fouillet et al. 2006; Grize et al. 2005; Rooney et al.1998), the United States (Semenza et al. 1999; Weisskopf et al. 2002) and other parts of the World (Tan et al. 2007) during the 1990s and the beginning of this century raises growing concerns regarding the relationship between the effects of extreme climatic episodes and individuals' health. 
Therefore, the number of studies linking extreme heat episodes with mortality and morbidity is increasing. Such studies can be subdivided into two groups: (1) studies that, according to this latter relationship, use temperature as an isolated climatic variable (Ballester et al. 1997; Hajat et al. 2002; Saez et al. 1995); (2) studies that combine climatic elements, such as temperature and relative humidity (Almeida et al. 2010; Michelozzi et al. 2006; Schiffano et al. 2009). Thee latter group had its genesis in the work developed by Steadman (1979a, b, 1984), which constituted a starting point for the creation of the "Heat Index", later adjusted by the United States National Weather Service for use as an anticipation alerting system for extreme heat events.

However, the effect of high temperature on mortality and morbidity can also be influenced by air pollution (Fischer et al. 2004; Stedman 2004; Grize et al. 2005; Tan et al. 2010). Increased ozone levels and particle concentration can contribute towards the aggravation of the number of deaths and hospitalizations during an extreme heat climatic episode (Anderson et al. 1996; Rooney et al. 1998). An underlying concern in this type of investigation lies in the identification of the main vulnerable groups, namely, the elderly population (Díaz et al. 2002a), which has a limited adaptation ability towards thermal stress factors (Jendritzky 1993), which necessitates the creation of adequate preventive measures against the effects of heat waves. The association between intense heat and physical debility in older people has been recognized in different studies, which also identify an increase in mortality when heat waves occur. During the 2006 heat wave, excess mortality among the elderly was observed in France (Fouillet et al. 2006; Rey et al. 2007), Vienna (Hutter et al. 2007), Holland (Huynen et al. 2001), and Barcelona (Borrel et al. 2006). Certain causes of death can even reflect the presence of chronic diseases that are triggered and aggravated during heat waves (Fouillet et al. 2006). Apart from the age factor, the importance of investigating individual vulnerability by gender has also been recognized (McGeehin and Mirabelli 2001).

Taking into account the health effects resulting from heat waves in individuals living in Mediterranean European climates, as well as those resulting from pollution concentration in Metropolitan areas, along with the progressive aging of the population from these countries, e.g., Portugal (Almeida et al. 2010), the objectives of this study were:

(1) To investigate the association between heat index and daily all-cause mortality, all-cause morbidity, respiratory morbidity, circulatory morbidity, and their lag time, for all-ages, $>74$ years and gender in Porto, Portugal, during the July 2006 heat wave;

(2) To determine if the levels of air pollution (ozone and particulate matter $-\mathrm{PM}_{10}$ ) might exacerbate the impact of heat waves on human-health, using modern statistical methods accounting for the confounding effects of ozone and PM.

\section{Materials and methods}

Study areas

The city of Porto is the second largest city in Portugal and is located in the Great Metropolitan Area of Porto (GMAP). The city is located in the northern region of the country, benefiting from a Mediterranean tempered climate, characterized by cold and rainy winters with hot and dry summers. Approximately 1.6 million people live in the GMAP, which, spatially distributed, represents a population density of 1,115 inhabitants $\mathrm{km}^{-2}$ (National Institute of Statistics 2001).

Health, climate and pollution data

Mortality data for Porto, from January to December (20022007), were obtained from the National Institute of Statistics. Mortality and daily admission counts due to all causes (except external causes), circulatory diseases and respiratory diseases were obtained from four hospitals within GMAP, using the fields "all patient diagnosis related groups" (AP-DRG) Version 21 (Biostatistics and Medical Informatics and Health System's Central Administration 2001).

Admission data were classified into four groups: one group for all-ages, another group for all-ages according to gender, another group for people over 74 years old, and another group for those over 74 years according to gender.

Daily meteorological variables of maximum temperature and relative humidity for Porto were obtained from the Meteorological Observatory of Serra do Pilar, located on the left bank of the Douro river, in the border town of Vila Nova de Gaia in Porto's municipality. The distance to the coast is approximately $5 \mathrm{~km}$. Although the station is relatively close to the center of Porto, it is not affected by the construction density and traffic of the city as it is located on the opposite bank of the Douro river, at an altitude of $93 \mathrm{~m}$.

We obtained daily atmospheric concentrations for ozone and $\mathrm{PM}_{10}$, measured at five locations (Antas, Ermesinde, Espinho, Custóias e Leça do Balio) in the GMAP, from the Portuguese Environment Agency (Fig. 1).

\section{Definition of heat-wave period}

Many methods exist for characterizing and definition a heat wave (Hajat et al. 2006, Huang et al. 2010).

We defined a heat wave as a period with at least 2 consecutive days with a heat index equal to or above degree III $(41<$ $\mathrm{HI}<54$ ). We thus identified the period from 11 to 19 July 2006 as a heat-wave. In order to calculate the heat index, defined as 

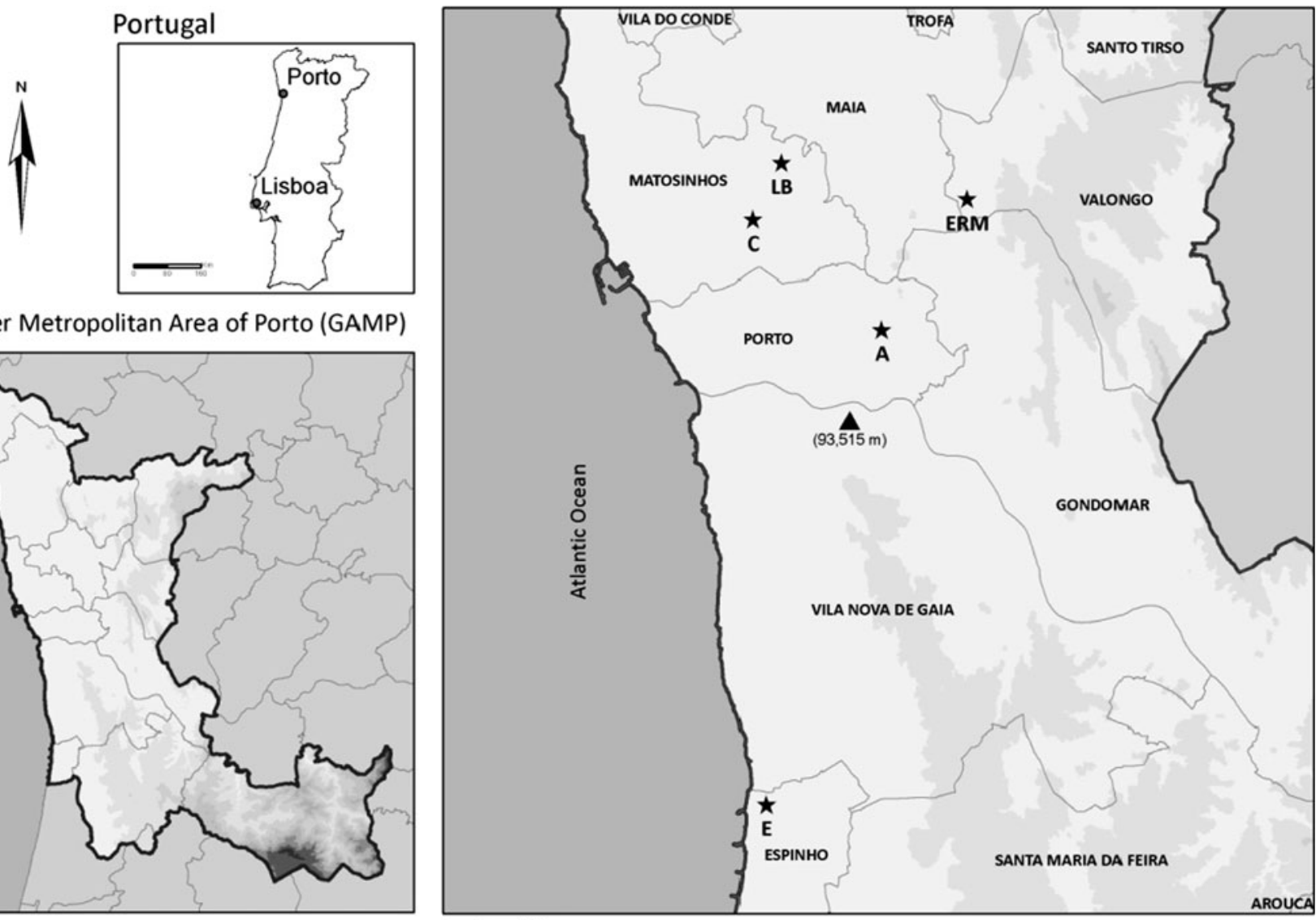

Greater Metropolitan Area of Porto (GAMP)
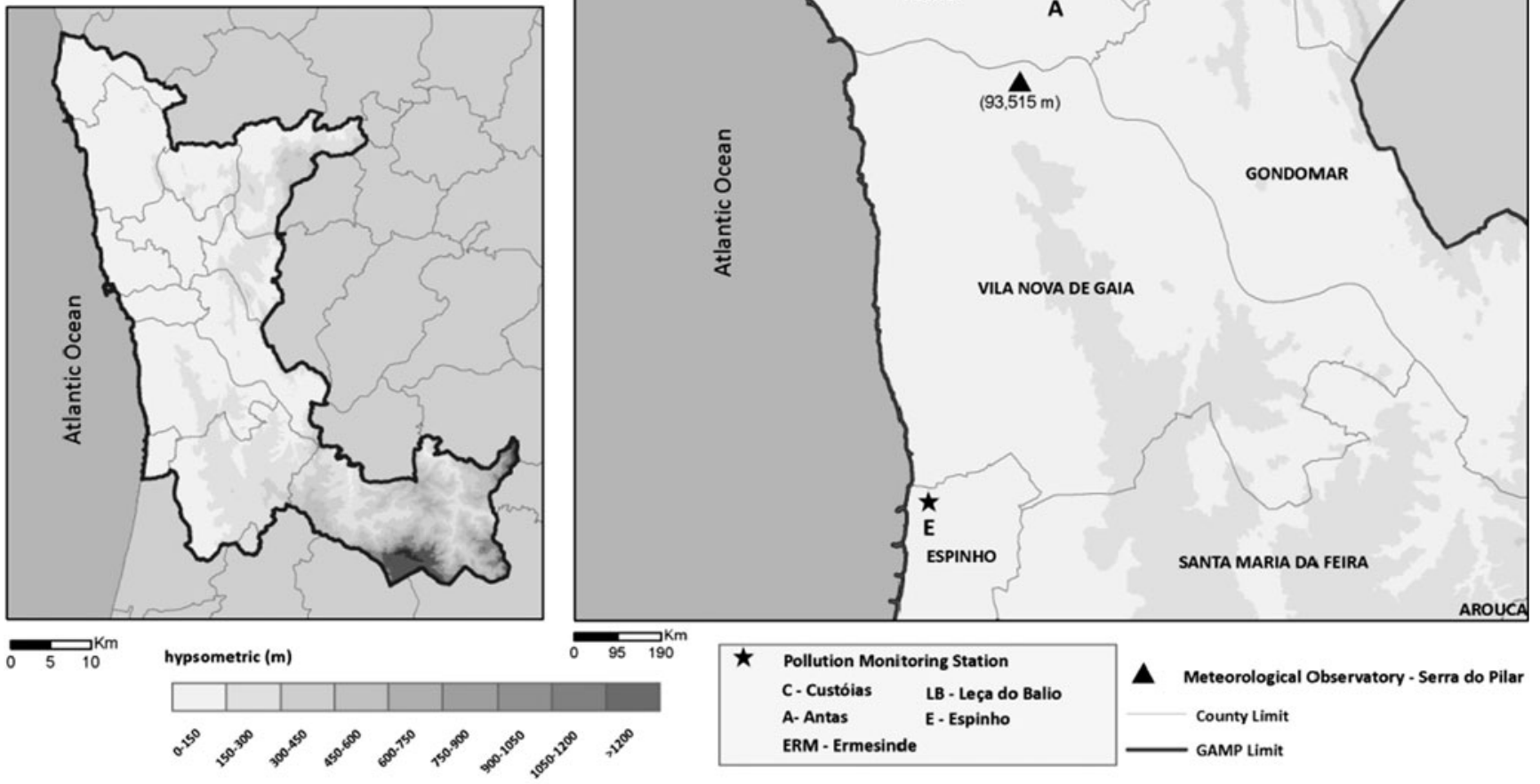

Source: IGP, 2008 CAOP; IGOE, Letters from Portugal Military - M888 Series (1998 and 1999)

Fig. 1 Geographical context of the meteorological observatory of Serra do Pilar

an individual's perceived air temperature, humidity and maximum temperature data were used. The heat index measures the evaporative heat between a typical human and the environment, and is a more appropriate measure to determine the effect of heat in the human body than temperature alone.

Statistical methods

\section{Heat index}

The heat index was calculated according to the following formula (Rothfusz 1990):

$$
\begin{aligned}
H I= & -42.379+(2.04901523 \times T)+(10.14333127 \times R) \\
& -(0.22475541 \times T \times R)-\left(6.83783 \times 10^{-3} \times T^{2}\right) \\
& -\left(5.4481717 \times 10^{-2} \times R^{2}\right)+\left(1.22874 \times 10^{-3} \times T^{2} \times R\right) \\
& +\left(8.5282 \times 10^{-4} \times T \times R^{2}\right)-\left(1.99 \times 10^{-6} \times T^{2} \times R^{2}\right)
\end{aligned}
$$

Where $T$ is air temperature $\left({ }^{\circ} \mathrm{C}\right)$, and $R$ is relative humidity $(\%)$.

\section{Excess of mortality and morbidity}

For further statistical analysis, we calculated an expected number of admissions by determining the average number of admissions (2002-2007, except 2006) recorded during 3 comparison weeks: the weeks prior to (3-10 July), corresponding to (11-18 July) and following (19-26 July) the heat wave. The expected number of admissions was subtracted from the number of admissions observed during the heat wave (11-18 July), in order to determine the existence of an excess in hospital admissions during the heat wave.

\section{Impact of heat on mortality and morbidity}

We investigated the impact of heat on mortality and morbidity due to all-causes, respiratory and circulatory morbidity, pneumonia, COPD, acute myocardial infarction, heart failure, cerebral vascular accident, for 3 weeks, during the week classified as an extreme heat event and 
in the previous and following week, using a Poisson regression model (Faraway 2006) for All Population,
Gender and Group Aged, expressed by the following formula:

$\operatorname{LOg}[\mu]=\beta_{0}+\beta_{1} X_{1}, \quad\left(\right.$ where $X_{1}$ represents the heat index and $\beta_{0}$ e $\beta_{1}$ are the regression coefficients models $)$

\section{Lag-time}

Additionally, the lag-time was studied, being this understood as the time interval exhibiting the highest association between the extreme heat event on day $t_{0}$ and the total admissions on day $t_{0+\mathrm{i}}$, with $\mathrm{i}=1,2, . .7$, through the Pearson correlation. The lag-time is considered an important aspect in public health studies (Hajat et al. 2002; Conti et al. 2005; Liang et al. 2008).

Therefore, for each day of the study period (during the heat wave, the previous and the following week) the correlation between the number of deaths/admissions and the heat index value registered (expressed by Pearson's $r$ ) was calculated. The lag-time varies from 0 (comparison between the total deaths/admissions and heat index of the same day) to 7 . The lag-time is the time in days presenting the highest correlation, according to the expression:

$r_{m}=\frac{n^{*} \sum\left(H I^{*} Y\right)-\sum H I \sum Y}{\sqrt{\left[n^{*} \sum(H I)^{2}-\left(\sum H I\right)^{2}\right]\left[n^{*} \sum(Y)^{2}-\left(\sum Y\right)^{2}\right]}}$

where $r_{\mathrm{m}}$ is the correlation coefficient lagged in $\mathrm{m}$ days $(\mathrm{m}=$ $1,2 \ldots 7$ days); $\mathrm{HI}$ is the heat index concerning the period $3-$ 26 July 2006, and $\mathrm{Y}$ is value of the dependent variable (mortality, morbidity, etc.) in the period 3-26 July 2006 if $\mathrm{m}=0,4-27$ July if $\mathrm{m}=1, \ldots$ in the period of 10 July -2 August 2006 if $\mathrm{m}=7$.

\section{Confounding effects}

In order to analyze pollution during the July 2006 heat wave, we calculated the daily ozone concentration and $\mathrm{PM}_{10}$ for all five monitoring stations considered in this study, from 3 to 26 July, i.e. covering the period prior to, during and following the heat wave (11-18 July).

\section{Results}

The calculation of HI allows the classification of temperature $\left({ }^{\circ} \mathrm{C}\right)$ according to four different danger levels to which possible physical symptoms correspond (National Weather Service Weather Forecast Office 2011): extreme danger
$\left(\mathrm{HI} \geq 54^{\circ} \mathrm{C}\right)$ - heat stroke or sunstroke; danger $(41<\mathrm{HI}<$ 54) - sunstroke, muscle cramps, and/or heat exhaustion, heatstroke with prolonged exposure and/or physical activity; extreme caution $(32<\mathrm{HI}<41)$ - sunstroke, muscle cramps, and/or heat exhaustion with possible prolonged exposure and/or physical activity; caution $(27<\mathrm{HI}<32)$ - possible fatigue with prolonged exposure and/or physical activity. In our work, the heat index can be correlated to excess mortality and respiratory admissions during a heat wave episode, as in July 2006, characterized by a combination of very high temperatures (from $29^{\circ} \mathrm{C}$ to $37^{\circ} \mathrm{C}$ ) and moderate relative humidity values ( $42 \%$ to $71 \%$ ). Thermal discomfort, which is liable to be observed ( 3 days from level II and 5 days from level III) can be explained by the combination of both these latter climatic elements, with the net result being an apparent temperature oscillating between 33 and $47^{\circ} \mathrm{C}$.

Excess mortality and morbidity (all-ages population)

From the beginning of the extreme heat event (11 July 2006) until its end (18 July 2006), from the group of studied variables (mortality and morbidity), it was the number of respiratory deaths and admissions that most closely matched the behavior of the apparent temperature (heat index). The circulatory morbidity tended to decrease, and morbidity due to all-causes remained relatively constant, with few oscillations (Fig. 2).

At Porto, an excess of 107 deaths occurred during the July 2006 heat wave, corresponding to $52 \%$ of the expected mortality and an increase of $2.7 \%(P<0.001)$ for a $1{ }^{\circ} \mathrm{C}$ increase in apparent temperature. The maximum association between heat index and mortality was felt with a lag period of 3 days $(r=0.67)$.

Morbidity due to all respiratory diseases presented an excess of 67 admissions, corresponding to an increase of $1.7 \%(P<0.004)$ for a $1{ }^{\circ} \mathrm{C}$ increase in apparent temperature. The maximum effect of heat index on admissions due to respiratory causes was seen with a lag period of 4 days $(r=0.76)$.

The specific cause of respiratory diseases presented a very significant excess of admissions, with an increase in COPD of $100 \%$ relative to the expected rate. For a $1^{\circ} \mathrm{C}$ increase in apparent temperature, we observed a $5.4 \%$ (95 \% CI: 1.0-6.6 \%) increase in COPD. The maximum 
Fig. 2 Number of deaths and admissions for the total population occurring during the extreme heat event (11-18 July 2006), during the previous week (3-10 July 2006) and in the following week (19-26 July 2006)

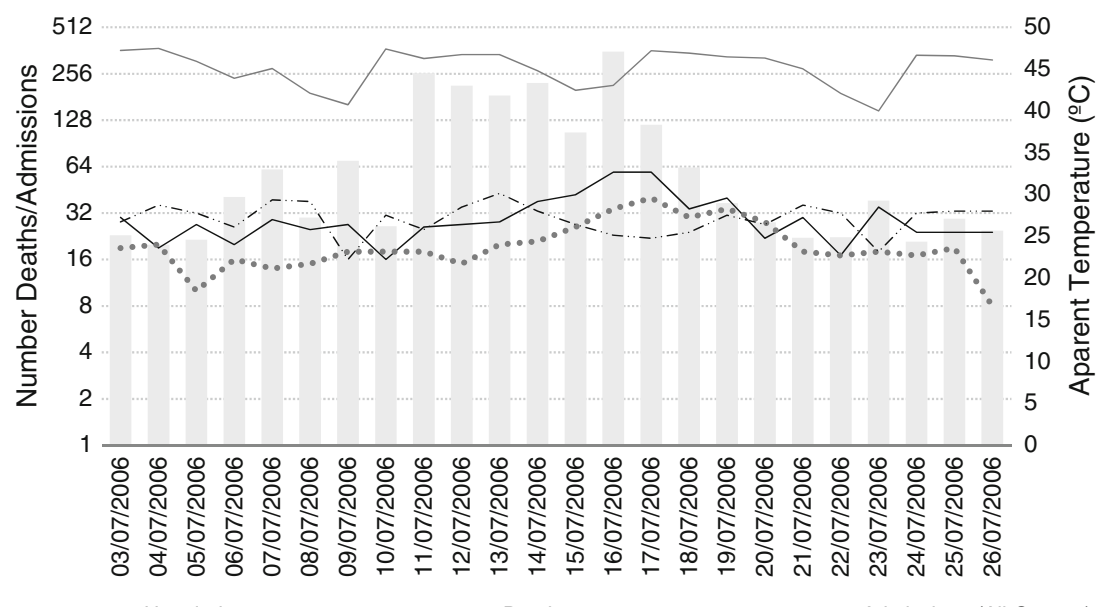

Heat index

..... Respiratory Admissions

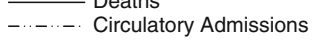

- Admissions (All-Causes) association between the heat index and COPD was observed with a lag time of 4 days $(r=0.61)$.

For morbidity due to heart failure, we observed a negative effect from heat $(r=-0.55)$. This maximum effect of heat was observed without the presence of a lag period (lag $=0$ days). We also observed a decrease in heart failure of $5.9 \%(95 \% \mathrm{CI}$ : $0.6-7.7)$ for a $1{ }^{\circ} \mathrm{C}$ increase in heat index.

For morbidity according to gender, we observed a heat effect in all cause morbidity for men $(P=0.045)$. However, we were not able to verify the existence of a significant correlation $(r<4.0)$, with or without lag, between total morbidity and the heat index.

Morbidity due to all respiratory causes presented an admissions' excess for the female gender of $2.2 \%(95 \%$ CI: $0.4-4.1$ ) for a $1{ }^{\circ} \mathrm{C}$ increase in apparent temperature.

For admissions due to specific respiratory causes, only COPD revealed a statistically significant admissions' excess of $7.5 \%$ for women ( $95 \%$ CI: $1.3-4.1$ ). Admissions due to COPD registered in women noted a small correlation with the heat index $(r=0.49)$, observed with a lag time of only 1 day (Table 1). Taking the additional effect of ozone into account did not produce an increase in either mortality or morbidity, regardless of the cause of admission. Moreover, the additional effect of ozone attenuated the effect of the heat index on respiratory morbidity. When the effect of $\mathrm{PM}_{10}$ was added to the heat index, a statistically significant increase was verified only for general mortality (from $2.7 \%$ to $4.0 \%$ ). The additional effect of $\mathrm{PM}_{10}$ resulted in a statistically significant decrease in the heat index's effect on morbidity due to all-causes, as well as in circulatory morbidity (Table 2).

\section{Excess morbidity (ages $\geq 75$ years)}

Morbidity behavior of individuals aged 75 years or above, during the extreme heat episode, was slightly different from that observed for the general population. Both respiratory morbidity and circulatory morbidity showed a sharp decrease at 3 and 4 days after the beginning of the event, respectively. After this drop, admissions due to respiratory and circulatory causes revealed a galloping growth until almost the end of the heat episode. In older individuals, only morbidity due to all-causes behaved analogously to the general population (Fig. 3). Excess admission in the older fraction of the population during the extreme climatic episode studied occurred only for general respiratory conditions and COPD.

Internment due to respiratory causes of the oldest individuals in the population showed a high correlation with the heat index $(r=0.74)$ at 4 days after the beginning of the extreme heat event. It should be added that, for each increase of $1{ }^{\circ} \mathrm{C}$ of the heat index, a growth of $3.3 \%$ in admissions due to respiratory diseases was observed (95\% CI: $1.7-5.0 \%)$.

COPD rate increased about $7.0 \%(95 \%$ CI: $1.1-3.2)$ for each $1{ }^{\circ} \mathrm{C}$ increase in the heat index. Admissions due to COPD also had an association with the heat index, although this was more moderate $(r=0.59)$, with a lag effect of 2 days.

Morbidity due to the general circulatory diseases in older individuals during the heat wave remained constant, with just a slight decrease of $2.1 \%$ (95\% CI: 6.1-9.7). Total circulatory morbidity also revealed an immediate negative association with the heat index ( $r=-0.45 \%)$, with no time lag between the beginning of the event and the effect on admissions. We observed a decrease of $4.8 \%$ (95 \% CI: $1.1-$ $9.5)$ in admissions due to heart failure in older individuals, and a small negative correlation $(r=-0.52)$ without time lag.

During the July 2006 heat wave, an excess of admissions due to respiratory diseases was observed, for individuals aged 75 years or above, with an increased statistical significance of $2.7 \%$ (95\% CI:0.4-5.1) for the men, and an increase of $3.9 \%$ (95\% CI:1.6-6.3) for women, for each $1{ }^{\circ} \mathrm{C}$ increase in the heat index. A maximum correlation 
Table 1 Excess mortality and morbidity during the heat wave that occurred from 11 July 2006 to 18 July 2006 calculated according to heat index. $O$ Observed, $E$ expected, $C O P D$ Chronic obstructive pulmonary disease

\begin{tabular}{|c|c|c|c|c|c|c|c|}
\hline Diagnosis & $\begin{array}{l}\mathrm{O} \\
\text { Excess }^{\mathrm{a}}\end{array}$ & $\mathrm{E}$ & $\begin{array}{l}(\mathrm{O}-\mathrm{E}) \\
(95 \% \mathrm{CI})\end{array}$ & $\begin{array}{l}\text { Lag time (days) } \\
\text { Pearson correlation }\end{array}$ & $r$ & $\begin{array}{l}\text { RR } \\
(95 \% \mathrm{CI}) \\
\text { Poisson regression }^{\mathrm{c}}\end{array}$ & $P$ \\
\hline Mortality $^{\mathrm{a}}$ & 313 & 206 & $107(52 \%)$ & 3 & 0.67 & $1.027(1.017-1.036)$ & $<0.001 * *$ \\
\hline All-cases mortality (total) & 2,395 & 2,370 & $25(1 \%)$ & - & $*$ & $0.997(0.994-1.000)$ & 0.065 \\
\hline All-cases mortality (men) & 1,034 & 1,072 & $-38(-4 \%)$ & - & $*$ & $0.995(0.990-1.000)$ & $0.045^{* *}$ \\
\hline All-cases mortality (women) & 1,361 & 1,266 & $95(8 \%)$ & - & $*$ & $0.995(0.994-1.003)$ & 0.498 \\
\hline Respiratory disease (total) & 204 & 137 & $67(49 \%)$ & 4 & 0.76 & $1.017(1.006-1.029)$ & $0.004 * *$ \\
\hline Respiratory disease (men) & 117 & 82 & $35(43 \%)$ & 3 & 0.68 & $1.014(0.999-1.029)$ & 0.074 \\
\hline Respiratory disease (women) & 87 & 55 & $32(58 \%)$ & - & $*$ & $1.022(1.004-1.041)$ & $0.017 * *$ \\
\hline Pneumonia (total) & 41 & 22 & $19(86 \%)$ & 4 & 0.61 & $1.017(0.991-1.044)$ & 0.212 \\
\hline Pneumonia (men) & 24 & 12 & $12(100 \%)$ & 5 & 0.60 & $1.031(0.995-1.068)$ & 0.091 \\
\hline Pneumonia (women) & 17 & 11 & $6(55 \%)$ & 4 & 0.44 & $1.001(0.962-1.041)$ & 0.973 \\
\hline COPD (total) & 24 & 12 & $12(100 \%)$ & 4 & 0.61 & $1.054(0.989-1.066)$ & $0.006^{* *}$ \\
\hline COPD (men) & 13 & 8 & $5(63 \%)$ & 4 & 0.49 & $1.040(0.990-1.091)$ & 0.118 \\
\hline COPD (women) & 11 & 4 & $7(175 \%)$ & 1 & 0.49 & $1.075(1.013-1.141)$ & $0.018^{* *}$ \\
\hline Circulatory disease (total) & 232 & 218 & $14(6 \%)$ & - & $*$ & $0.995(0.897-1.005)$ & 0.353 \\
\hline Circulatory disease (men) & 111 & 110 & $1(1 \%)$ & - & $*$ & $0.993(0.979-1.007)$ & 0.307 \\
\hline Circulatory disease (women) & 121 & 108 & $13(12 \%)$ & - & $*$ & $0.998(0.984-1.012)$ & 0.775 \\
\hline Acute myocardial infarction (total) & 15 & 19 & $-4(-21 \%)$ & - & $*$ & $0.965(0.926-1.005)$ & 0.088 \\
\hline Acute myocardial infarction (men) & 8 & 10 & $-2(-20 \%)$ & - & * & $0.949(0.897-1.004)$ & 0.070 \\
\hline Acute myocardial infarction (women) & 7 & 9 & $-2(-22 \%)$ & - & $*$ & $0.986(0.928-1.048)$ & 0.646 \\
\hline Heart failure (total) & 16 & 20 & $-4(-20 \%)$ & 0 & -0.55 & $0.941(0.906-0.977)$ & $0.002 * *$ \\
\hline Heart failure (men) & 11 & 9 & $2(22 \%)$ & - & $*$ & $0.977(0.932-1.024)$ & 0.329 \\
\hline Heart failure (women) & 5 & 12 & $-7(-58 \%)$ & 0 & -0.61 & $0.896(0.840-0.957)$ & $<0.001 * *$ \\
\hline Cerebral vascular accident (total) & 31 & 28 & $3(11 \%)$ & - & $*$ & $0.981(0.953-1.009)$ & 0.183 \\
\hline Cerebral vascular accident (men) & 17 & 14 & $3(21 \%)$ & - & $*$ & $0.978(0.941-1.017)$ & 0.260 \\
\hline Cerebral vascular accident (women) & 14 & 14 & $0(0 \%)$ & - & $*$ & $0.984(0.944-1.026)$ & 0.460 \\
\hline
\end{tabular}

*Pearson correlation $<0.40, * * P<0.05$

${ }^{a}$ Excess mortality and admissions during the heat wave that occurred from 11 July 2006 to 18 July 2006, calculated according to heat index

${ }^{\mathrm{b}}$ Estimated lag time for mortality and morbidity for all-ages during the heat wave week, the previous week and following week

${ }^{\mathrm{c}}$ Percentage increase ( $95 \%$ confidence interval) in daily mortality and morbidity for a $1^{\circ} \mathrm{C}$ increase in heat index, for all-ages, during the heat wave week, the previous week and following week

between the heat index and the number of admissions due to respiratory causes was also observed for both men $(\mathrm{r}=0.56)$ and women $(\mathrm{r}=0.78)$, with a lag time of 2 and 4 days, respectively (Table 3 ).

The additive effect of ozone in the heat index did not represent an aggravating factor in the older population's morbidity, regardless of cause. The addition of PM10 revealed a statistically significant decrease of the effect of the heat index on all-cause morbidity for the older population (> 74 years). The inclusion of $\mathrm{PM}_{10}$ led to a significant increase only in the effect of respiratory morbidity of the population aged over 74 years (from $3.3 \%$ to $3.4 \%$ ) (Table 4).

\section{Discussion}

Number of heat wave days and daily temperatures

The July 2006 heat wave was characterized by the presence of several days at level II and III of the heat index. The physiological symptoms associated with level II $\left(32^{\circ} \mathrm{C}-40^{\circ}\right.$ C) are possible sunstroke, muscle cramps, heat exhaustion with prolonged exposure and physical activity, while those associated with level III $\left(41^{\circ} \mathrm{C}-53^{\circ} \mathrm{C}\right)$ are similar, with the possible additional occurrence of heat stroke with prolonged exposure and/or physical activity. In this study, the use of the heat index constituted an important criterion with which 
Table 2 Percentage increase ( $95 \%$ confidence interval) in all-causes mortality, all-causes morbidity, respiratory morbidity and circulatory morbidity for a $1^{\circ} \mathrm{C}$ increase in Heat Index, adjusted by each individual pollutant, for all-ages population

$* P<0.05$

\begin{tabular}{|c|c|c|c|c|}
\hline \multirow[t]{2}{*}{ Diagnosis } & \multicolumn{2}{|l|}{$\begin{array}{l}\text { RR }(95 \% \text { CI }) \\
\text { Heat index }\end{array}$} & \multicolumn{2}{|l|}{ Heat index } \\
\hline & + Ozone & & + Particulate matter & \\
\hline \multicolumn{5}{|c|}{ All-causes mortality } \\
\hline All & $1.006(0.992-1.021)$ & 0.414 & $1.040(1.023-1.056)$ & $<0.001^{*}$ \\
\hline \multicolumn{5}{|c|}{ All-causes morbidity } \\
\hline All & $0.992(0.987-0.997)$ & $0.001 *$ & $0.961(0.956-0.967)$ & $<0.001 *$ \\
\hline Men & $0.993(0.986-1.000)$ & 0.052 & $0.961(0.952-0.970)$ & $<0.001^{*}$ \\
\hline Women & $0.991(0.985-0.998)$ & $0.008^{*}$ & $0.962(0.954-0.970)$ & $<0.001^{*}$ \\
\hline \multicolumn{5}{|c|}{ Respiratory morbidity } \\
\hline All & $0.994(0.976-1.012)$ & 0.503 & $1.018(0.998-1.039)$ & 0.082 \\
\hline Men & $0.993(0.970-1.012)$ & 0.527 & $1.019(0.992-1.045)$ & 0.168 \\
\hline Women & $0.996(0.968-1.025)$ & 0.774 & $1.018(0.985-1.051)$ & 0.288 \\
\hline \multicolumn{5}{|c|}{ Circulatory morbidity } \\
\hline All & $0.989(0.974-1.004)$ & 0.149 & $0.975(0.957-0.993)$ & $0.007 *$ \\
\hline Men & $0.993(0.976-1.014)$ & 0.529 & $0.965(0.940-0.991)$ & $0.009^{*}$ \\
\hline Women & $0.984(0.973-1.004)$ & 0.156 & $0.985(0.960-1.011)$ & 0.250 \\
\hline
\end{tabular}

to assess respiratory morbidity. The heat index is an alert system that combines temperature with humidity, generating an apparent temperature and corresponding physiological limits (Kovats and Ebi 2006). However, the capacity to evaluate susceptibility to extreme events requires the study of alerting systems that better translate into health effects. There are other alerting systems for heat waves, it being possible to differentiate between those that simply use the temperature above certain limits (Koppe et al. 2003) and those including synoptic methods associated to specific air masses that explain high mortality days, as well as those presenting temporal series models, capable of describing a relationship between thermal discomfort and mortality in a more revealing way (Kyselý 2004).
Mortality/morbidity excess (all-ages)

Comparison of observed and expected mortality/morbidity during the 2006 heat wave revealed a mortality excess of $52 \%$ (107 admissions), a morbidity (all-causes) excess of $1 \%$ (25 hospital admissions), a respiratory morbidity excess of $49 \%$ (67 hospital admissions) and a circulatory morbidity excess of $6 \%$ (14 hospital admissions) in the GMAP area.

The excess mortality associated with extreme heat climatic episodes seen in our study was also reported in several other European countries during the 2003 and 2006 heat waves (Nogueira et al 2005; Simon et al. 2005; Conti et al. 2005; Johnson et al. 2005; Garssen et al. 2005 and Grize et al. 2005; Fouillet et al. 2006).
Fig. 3 Number of deaths and admissions in the population aged 75 years and above during the extreme heat event (11-18 July 2006), the previous week (3-10 July 2006) and the following week (19-26 July 2006)

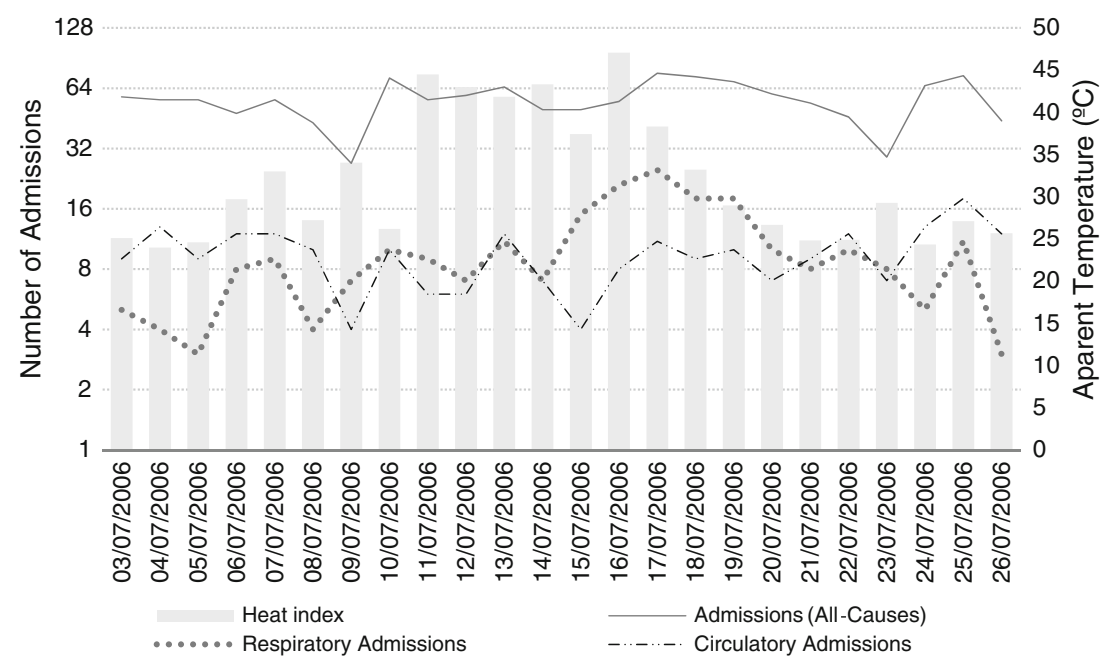


Table 3 Excess mortality and morbidity for the older population ( $\geq 75$ years) during the heat wave that occurred from 11 July 2006 to 18 July 2006 calculated according to heat index

\begin{tabular}{|c|c|c|c|c|c|c|c|}
\hline Diagnosis & $\mathrm{O}$ & $\mathrm{E}$ & $\begin{array}{l}\text { Excess }(95 \% \text { CI }) \\
\text { Excess }\end{array}$ & $\begin{array}{l}\text { Lag time (days) } \\
\text { Pearson Correlation }\end{array}$ & $r$ & $\begin{array}{l}\text { RR }(95 \% \text { CI }) \\
\text { Poisson Regression }\end{array}$ & $\rho$ \\
\hline Mortality* & $\mathrm{b}$ & $\mathrm{b}$ & $\mathrm{b}$ & $\mathrm{b}$ & $\mathrm{b}$ & $\mathrm{b}$ & $\mathrm{b}$ \\
\hline All-cause morbidity (total) & 484 & 397 & $87(22 \%)$ & 4 & 0.42 & $1.001(0.994-1.008)$ & 0.796 \\
\hline All-cause morbidity (men) & 187 & 172 & $15(9 \%)$ & - & $*$ & $0.992(0.981-1.00)$ & 0.172 \\
\hline All-cause morbidity (women) & 297 & 224 & $73(33 \%)$ & 1 & 0.55 & $1.007(0.998-1.017)$ & 0.128 \\
\hline Respiratory disease (total) & 113 & 54 & $59(109 \%)$ & 4 & 0.74 & $1.033(1.017-1.050)$ & $<0.001 * *$ \\
\hline Respiratory disease (men) & 53 & 28 & $25(89 \%)$ & 2 & 0.56 & $1.027(1.004-1.051)$ & $0.023 * *$ \\
\hline Respiratory disease (women) & 60 & 25 & $35(140 \%)$ & 4 & 0.78 & $1.039(1.016-1.063)$ & $<0.001 * *$ \\
\hline Pneumonia (total) & 25 & 11 & $14(127 \%)$ & 5 & 0.58 & $1.027(0.993-1.062)$ & 0.127 \\
\hline Pneumonia (men) & 12 & 5 & $7(140 \%)$ & 2 & 0.60 & $1.038(0.986-1.092)$ & 0.153 \\
\hline Pneumonia (women) & 13 & 6 & $7(117 \%)$ & 5 & 0.44 & $1.018(0.973-1.065)$ & 0.438 \\
\hline COPD (total) & 12 & 6 & $6(100 \%)$ & 2 & 0.59 & $1.070(1.011-1.132)$ & $0.019 * *$ \\
\hline COPD (men) & 5 & 4 & $1(20 \%)$ & 2 & 0.45 & $1.053(0.974-1.138)$ & 0.196 \\
\hline COPD (women) & 7 & 2 & $5(250 \%)$ & 2 & 0.44 & $1.090(1.003-1.185)$ & $0.042 * *$ \\
\hline Circulatory disease (total) & 63 & 62 & $1(2 \%)$ & 0 & -0.45 & $0.979(0.961-0.997)$ & $0.026^{* *}$ \\
\hline Circulatory disease (men) & 27 & 25 & $2(13 \%)$ & - & $*$ & $0.974(0.947-1.000)$ & 0.054 \\
\hline Circulatory disease (women) & 36 & 37 & $-1(-3 \%)$ & - & $*$ & $0.984(0.958-1.010)$ & 0.223 \\
\hline Acute myocardial infarction (total) & 5 & 8 & $3(-38 \%)$ & - & $*$ & $0.960(0.900-1.025)$ & 0.225 \\
\hline Acute myocardial infarction (men) & 1 & 3 & $-2(-67 \%)$ & - & $*$ & $0.921(0.814-1.041)$ & 0.186 \\
\hline Acute myocardial infarction (women) & 4 & 5 & $-1(-20 \%)$ & - & $*$ & $0.982(0.909-1.062$ & 0.656 \\
\hline Heart failure (total) & 11 & 13 & $2(-15 \%)$ & 0 & -0.52 & $0.952(0.911-0.995)$ & $0.028 * *$ \\
\hline Heart failure (men) & 7 & 4 & $3(75 \%)$ & 3 & -0.43 & $0.999(0.942-1.059)$ & 0.964 \\
\hline Heart failure (women) & 4 & 8 & $-4(-50 \%)$ & 0 & -0.59 & $0.907(0.845-0.974)$ & 0.007 \\
\hline Cerebral vascular accident (total) & 14 & 13 & $1(8 \%)$ & 3 & -0.4 & $0.987(0.948-1.028)$ & 0.537 \\
\hline Cerebral vascular accident (men) & 7 & 5 & $2(40 \%)$ & - & $*$ & $0.986(0.933-1.043)$ & 0.628 \\
\hline Cerebral vascular accident (women) & 7 & 8 & $-1(13 \%)$ & - & $*$ & $0.988(0.932-1.048)$ & 0.699 \\
\hline
\end{tabular}

*Pearson correlation $<0.40, * * P<0.05$

${ }^{a}$ Excess admissions during the heat wave of 11-18 July 2006, calculated according to heat index, for the older population ( $\geq 75$ years)

${ }^{\mathrm{b}}$ Estimated lag time for mortality and morbidity in the older population ( $\geq 75$ years), during the heat wave week, the previous week and following week

${ }^{\mathrm{c}}$ Percentage increase $\left(95 \%\right.$ confidence interval) in daily mortality and morbidity for a $1{ }^{\circ} \mathrm{C}$ increase in heat index, in the older population ( $\geq$ 75 years), during the heat wave week, the previous week and following week

The highest number of deaths relative to the number expected presented a maximum correlation on the 3rd day, where the value of the heat index was greater than or equal to $42^{\circ} \mathrm{C}$. Thereafter, this association decreased, as was also observed in the study of Kyselý (2004). The high excess mortality experienced during the extreme heat event, and the quantification of its growth $(2.7 \%)$ for each $1{ }^{\circ} \mathrm{C}$ increase of the heat index is also similar to the results presented in the study of Almeida et al (2010), which refers to an excess of $2.1 \%$.

From the studied causes of morbidity, general respiratory causes and specific associated causes, namely, COPD, revealed an admission excess during the heat wave of July 2006. This result is consistent with previous studies relating heat waves with mortality due to respiratory diseases. Other authors have reported similar results while revealing a mortality excess due to respiratory causes during heat wave episodes (Kilbourne 1999; Rey et al. 2007). Likewise, Huynen et al. (2001) found an association between increased mortality due to respiratory causes and different heat waves registered in Holland. Hertel et al. (2009) observed an association between respiratory causes and the 2003 heat wave in Germany.

In our study, the maximum number of admissions for respiratory conditions and COPD was seen mainly on the 4th consecutive day with heat index greater than or equal to $42^{\circ} \mathrm{C}$. This latter result seems to be concordant with the study of Mastrangelo et al. (2007), which verified the existence of an association between hospital admissions due to respiratory diseases and sequences of at least 4 days with Humidex index above $40^{\circ} \mathrm{C}$ in the summers of 2002 and 2003 in the Veneto Region of Italy. 
Table 4 Percentage increase (95\% confidence interval) in all-causes mortality, all-causes morbidity, respiratory morbidity and circulatory morbidity for a $1{ }^{\circ} \mathrm{C}$ increase in heat index, adjusted by individual pollutant, in the older population ( $\geq 75$ years)

$* P<0.05$

\begin{tabular}{|c|c|c|c|c|}
\hline \multirow[t]{2}{*}{ Diagnosis } & \multicolumn{2}{|l|}{$\begin{array}{l}\text { RR }(95 \% \mathrm{CI}) \\
\text { Heat index }\end{array}$} & \multicolumn{2}{|l|}{ Heat index } \\
\hline & + Ozone & & + Particulate matter & \\
\hline \multicolumn{5}{|c|}{ All-causes morbidity } \\
\hline All >74 years & $0.993(0.988-1.006)$ & 0.192 & $0.975(0.962-0.988)$ & $<0.001^{*}$ \\
\hline Men $>74$ years & $0.991(0.977-1.005)$ & 0.262 & $0.971(0.962-0.992)$ & $0.006^{*}$ \\
\hline $\begin{array}{l}\text { Women }> \\
74 \text { years }\end{array}$ & $0.994(0.988-1.013)$ & 0.444 & $0.977(0.960-0.994)$ & $0.009^{*}$ \\
\hline \multicolumn{5}{|c|}{ Respiratory morbidity } \\
\hline All $>74$ years & $1.012(1.000-1.044)$ & 0.355 & $1.034(1.005-1.064)$ & $0.019^{*}$ \\
\hline Men $>74$ years & $1.001(0.982-1.045)$ & 0.978 & $1.038(0.997-1.080)$ & 0.070 \\
\hline $\begin{array}{l}\text { Women }> \\
74 \text { years }\end{array}$ & $1.023(1.001-1.062)$ & 0.201 & $1.031(0 . .991-1.073)$ & 0.131 \\
\hline \multicolumn{5}{|c|}{ Circulatory morbidity } \\
\hline All > 74 years & $0.977(0.979-1.005)$ & 0.092 & $0.968(0.936-1.001)$ & 0.058 \\
\hline Men $>74$ years & $0.992(0.951-1.015)$ & 0.661 & $0.972(0.926-1.012)$ & 0.249 \\
\hline Women $>74$ years & $0.961(0.996-1.067)$ & 0.052 & $0.9764(0.919-1.011)$ & 0.130 \\
\hline
\end{tabular}

A possible explanation can be found in an idea presented by Mastrangelo et al. (2007), stating that the ideal conditions for increasing hospital admissions are a sequence of at least 4 consecutive hot and humid days. As the author states, from a physiological point of view, respiratory difficulty occurs as a result of the accumulation of heat and humidity over time. Simultaneously, evaporative capacity is reduced, making an organism's sudation and cooling functions less effective. Simultaneously, evaporation capacity becomes smaller, making it difficult for an organism's sudation and cooling functions to occur (Frota and Schiffer 1987).

In our study, for each $1^{\circ} \mathrm{C}$ increase in the heat index, a $1.7 \%$ growth in respiratory morbidity was registered, which is slightly less than the respiratory mortality rate reported by Almeida et al. (2010). In his study, an increase of $1^{\circ} \mathrm{C}$ in the daily average apparent temperature corresponded to an increase of $2.7 \%$ in mortality due to respiratory causes during the hot season.

Myocardial infarction, which belongs to the group of cardiovascular diseases, shows a lag period of 0 days between the beginning of the extreme heat episode and hospital admissions, with admissions diminishing from the $1 \mathrm{st}$ day of the extreme event onwards. For each increase in $1^{\circ} \mathrm{C}$ of the heat index, a decay in admissions of $5.9 \%$ was registered. This fact is corroborated by a study performed in 12 European cities, which found that an increase in high temperatures contributed to an increase in cardiovascular mortality without seeing an increase in morbidity due to cardiovascular causes (Michelozzi et al. 2009). The extreme heat phenomenon can cause an increase in the immediate death of individuals suffering from heart failure, consequently decreasing the capacity of these individuals to arrive at hospital admission centers in time. This idea seems to concur with other studies that highlight the underestimation of circulatory causes. Several studies performed in different geographical contexts, e.g., London (Kovats and Ebi 2006), Veneto (Mastrangelo et al. 2007), Chicago (Semenza et al. 1996; Whitman et al. 1997), Madrid (Linares and Díaz 2007) and Holland (Huynen et al. 2001) found that the time between exposure to heat and death due to circulatory causes is short. Therefore, the immediate effect of heat on the human organism will contribute towards an apparent reduction in the hospitalization of these individuals.

Our results allow a small distinction to be made between the heat waves' effects according to gender and for the general population irrespective of age, namely, for excess admissions due to respiratory disease and COPD in women. An analogous excess mortality occurred in France during the 2003 heat wave (Pirard et al. 2005), and in Chicago during the 2005 heat wave (Whitman et al. 1997) effects were higher among Women. However, other studies (Ellis and Nelson 1975; Ellis et al. 1975) evaluating the effects of heat on mortality in New York during the 1970s saw no differences between genders. Considering these differences between results, there is still no consensus on the effects of heat waves according to gender (Basu and Samet 2002). No significant increase relative to expected admissions was observed for general circulatory diseases and cerebral vascular accidents, either for total admissions or for admissions by gender during the heat wave. However, admissions due to heart failure in women decreased by $10.4 \%(95 \% \mathrm{CI}$ : $0.84,0.96)$ for each $1^{\circ} \mathrm{C}$ increase in the heat index. The addition of ozone to the heat index led to a decrease in the effect of all-cause morbidity in our study, which is in accordance with the results of Bouchama and Knochel (2002), but opposite to results published by the World Health Organization 
(WHO 2004) and Anderson et al. (1996), which concluded that total daily mortality is expected to increase with increasing ozone levels.

The inclusion of air pollutants to study their confounding and modifying effects revealed a significant effect when adjusting for $\mathrm{PM}_{10}$ for all-cause mortality. The influence of $\mathrm{PM}_{10}$ is consistent with that reported by Stedman (2004), who observed a mortality excess during high $\mathrm{PM}_{10}$ concentrations. However, this result differs from other studies (Almeida et al. 2010; Basu et al. 2008) which found no significant association between mortality and apparent temperature when considering $\mathrm{PM}_{10}$ in Porto and California, respectively.

\section{Morbidity excess $>75$ years}

The results from this study also reveal a significant increase in admission for some respiratory diseases (3.3\%) and COPD $(7.0 \%)$ in people over 74 years of age during the heat wave period. Admissions for respiratory causes in individuals older than 74 years show an equal or smaller lag period in relation to the general population. This fact seems to demonstrate the effect of heat in the aged human body, which shows a higher vulnerability in individuals aged more than 74 years.

Excess hospital admissions for individuals in this age group due to all circulatory causes, pneumonia, myocardial infarction, and cerebral vascular accident were not observed. The number of heart failure admissions during the July 2006 heat episode revealed a decrease. This morbidity behavior in the most fragile individuals, such as the elderly, corroborates the idea that intense heat will potentiate immediate death in individuals susceptible to the development of circulatory diseases. The effects of heat wave episodes are more evident in the elderly population, as higher temperature increases blood viscosity, precipitating an increase in thrombosis and a deficiency in thermoregulatory function (Keatinge et al. 1986). One possible explanation for deaths could be the existence of a heart failure excess in individuals of advanced age. This can be explained by an age-related decrease in filling during the left ventricular diastole, limiting cardiac debt and cardiac frequency during rest or physical exercise (Schulman et al. 1992; Kenney 1997). Another possibility is based on the fact that age also leads to lower activity of cutaneous vessels, limiting the body's capacity to disperse heat from the body's core to the skin at times of intense heat (Rooke et al. 1994). The higher risk of death by heart failure in the elderly can be due to the fact that this group generally exhibits inadequate water consumption during high thermal stress conditions when heat strikes, which contributes towards a lower adaptation (Semenza et al. 1999).

Morbidity due to all causes in the group of individuals aged more than 74 years revealed a statistically significant increase for the female gender in admissions for general respiratory diseases and pneumonia. Other studies have highlighted older women as the group with the highest mortality proportion in extreme heat situations (Klinenberg 2002; Whitman et al. 1997). The fact that women have a higher average life expectancy than men is considered as one possible explanation for this higher mortality and admission rate (Fouillet et al. 2006). However, this argument was not supported in our study, which included comparison between samples with the same characteristics at distinct temporal moments.

The association of $\mathrm{PM}_{10}$ with the heat index in order to study its modifying effects found, in our study, an increasing effect on respiratory morbidity in the older population (> 74 years). However, a study by Almeida et al. (2010) observed that inclusion of particulate matter in the analysis revealed a decreasing effect of the respiratory morbidity in individuals above 65 years of age.

\section{Final considerations}

Firstly, in the context of a temperate Mediterranean climate during days with high apparent temperature, all-causes mortality, and admissions due to all respiratory causes and COPD increased significantly for the general population. For the group including all-ages, between-gender differences were significant for morbidity due to respiratory disease, COPD and heart failure. Women were most affected by all respiratory causes and COPD on such days. Admissions due to all-causes of morbidity for men and admissions due to heart failure for women decreased during this extreme heat climatic event.

For the age group above 74 years of age, respiratory morbidity increased not only for women but also for men. Admissions for COPD were more evident in older women than in older men. Admissions due to circulatory and heart failure in the older population decreased during the heat wave, probably due to an immediate increase in mortality due to these causes. However, we suggest that future studies investigate the relationship between heat waves in mortality and morbidity from both causes simultaneously.

Secondly, the lag time between the extreme heat event of July 2006 revealed an association with total mortality for 3 days. Mortality of the general population due to all causes, pneumonia and COPD revealed a slightly higher lag period of 4 days. The lag time seems to be somewhat reduced ( 2 days) for admissions due to respiratory causes in those aged above 74 years.

Thirdly, only $\mathrm{PM}_{10}$ constituted an aggravating factor in all-causes mortality of individuals for the entire population and an aggravating factor in the respiratory morbidity for the population above 74 years of age when added to the heat index effect. Ozone levels did not exacerbate the human health impact of heat waves in our study. 
Strategies for prevention of, or minimizing, excess mortality and morbidity in extreme heat events aimed at minimization of vulnerability require the inclusion of preventive measures that attribute specific importance to risk groups, implying knowledge of the local population's characteristics (Michelozzi et al. 2006). Transfer of this information to public in general, and to the age groups at risk in particular, assumes great importance. It is important to inform the population about the main symptoms of the effects of heat in health (Naughton et al. 2002). Recognition of the effects of heat in health could contribute towards modification of risk behaviors, as well as to the awareness of the physical symptoms of exposure to heat, which could contribute to activating faster intervention mechanisms when emergency situations occur. In the case of the population's most vulnerable groups, such as older people and patients, daily surveillance of their physical condition and their environmental context by family, neighbours or care assistants is of fundamental importance.

\section{Limitations}

The first limitation of this study results from the fact that it did not include data on the causes of mortality, which complicates understanding of the decrease in circulatory morbidity and heart failure morbidity. It is however necessary to investigate the consequences of these events according to their pathological causes, even for mortality or morbidity simultaneously, as they might demand different intervention strategies. The second limitation lies in the fact that the effects of the urban heat island on excess mortality and morbidity have not been studied when heat waves occur in urban areas. Although such factors can impact on excess mortality and morbidity (Buechley et al. 1972; Tan et al. 2007), the required climatic data for the study period and locations inside Porto were unavailable.

Acknowledgments We would like to thank $\mathrm{Dr}^{\mathrm{a}}$. Fátima Candoso (Health System Central Administration) and Dr. Fernando Lopes (São João Hospital) for support.

Competing interests The authors declare that they have no competing interests.

\section{References}

Almeida S, Casimiro E, Calheiros J (2010) Effects of apparent temperature on daily mortality in Lisbon and Porto, Portugal. Environ Health 9:12. doi:10.1186/1476-069X-9-12

Anderson H, Ponce de Leon A, Bland M et al (1996) Air pollution and daily mortality in London: 1987-92. BMJ 312:665-669

Ballester F, Corella D, Perez-Hoyos S, Sáez M, Hervás A (1997) Mortality as a function of temperature: a study in Valencia, Spain, 1991-1993. Int J Epidemiol 26:551-561

Ballester J, Giorgi F, Rodo X (2010) Changes in European temeprature extremes can be predicted from changes in PDF central statistics.
Climatic Change 98:277-284. doi:10.1007/s10584-009-9758OLETTER

Basu R, Samet J (2002) Relation between elevated ambient temperature and mortality: a review of the epidemiologic evidence. Epidemiol Rev 24:190-202

Basu R, Feng W, Ostro B (2008) Characterizing temperature and mortality in nine California counties. Epidemiology 19(1):138145. doi:10.1097/EDE.0b013e31815c1da7

Biostatistics and Medical Informatics and Health System's Central Administration (2001) The heat index "equation." National Weather Service Technical Attachment P - Portal de Codificação dos GDH. Available from http://portalcodgdh.min-saude.pt/ index.php/All_Patient_Diagnosis_Related_Groups_(AP-DRG) (Accessed 10 February 2011)

Borrel C, Dell'Olmo M, Rodríguez-Sanz M, Garcia-Olalla P, Cayla J, Benach J, Muntaner C (2006) Socioeconomic position and excess mortality during the heat wave of 2003 in Barcelona. Eur J Epidemiol 21:633-640. doi:10.1007/s10654-006-9047-4

Bouchama A, Knochel J (2002) Heat stroke. N Engl J Med 346 (25):1978-1988

Buechley R, Van Bruggen J, Truppi L (1972) Heat island equals death island? Environ Res 5(1):85-92

Calado R, Nogueira P, Catarino J, Paixão E, Botelho J, Carreira M, Falcão J (2004) A onda de calor de Agosto de 2003 e os seus efeitos sobre a mortalidade da população portuguesa. Revista Portuguesa de Saúde Pública 22(2):7-20

Conti S, Meli P, Minelli G et al (2005) Epidemiologic study of mortality during the summer 2003 heat wave in Italy. Environ Res 98(3):390-399. doi:10.1016/j.envres.2004.10.009

Dessai S (2002) Heat stress mortality in Lisbon part I-model construction and validation. Int J Biometeorol 47:6-12

Dessai S (2003) Heat stress mortality in Lisbon part II — an assessment of the potential impacts of climate change. Int $\mathrm{J}$ Biometeorol 48:37-44. doi:10.1007/s00484-003-0180-4

Díaz J, Garcia R, Lopez C, Jordan A (2002a) Heat waves in Madrid 1986-1997: effects on the health of the elderly. Int Arch Occup Environ Health 75:163-170. doi:10.1007/s00420-0010290-4

Díaz J, Garcia R, Velasquez de Castro F, Hernandez E, Lopez C, Otero A (2002b) Effects of extremely hot days on people older than 65 years in Seville (Spain) from 1986 to 1997. Int J Biometeorol 46:145-149. doi:10.1007/s00484-002-0129-z

Díaz J, Garcia-Herrera TR, Linares C (2006) The impact of summer 2003 heat wave in Iberia: how should we measure it? Int J Biometeorol 50:159-166. doi:10.1007/s00484-005-0005-8

D'lppoliti D, Michelozzi P, Marino C, Donato F, Menne B, Katsouyanni K, Kirchmayer U, Analitis A, Medina-Ramón M, Paldy A, Atkinson R, Kovats S, Bisanti L, Schneider A, Lefranc A, Iñiguez C, Perucci C (2010) The impact of heat waves on mortality in 9 European cities: results from the EuroHEAT project. Environ Health 9:37. doi:10.1186/1476-069X-9-37

Ellis F, Nelson F (1975) Mortality in the elderly in a heat wave in New York City. Environ Res 978(15):504-512

Ellis F, Nelson F, Pincus L (1975) Mortality during heat waves in New York City July, 1972 and August and September, 1973. Environ Res 10:1-13

Faraway J (2006) Extending the Linear Model with R. Generalized linear, mixed effects and nonparametric regression models. Chapman and Hall/CRC, London

Fischer P, Brunekreef B, Lebret E (2004) Air pollution related deaths during the 2003 heat wave in the Netherlands. Atmos Environ 38:1083-1085

Fouillet A, Rey G, Laurent F, Pavillon G, Bellee S, GuihenneueJouyaux CJ, Jougla E, Hémon D (2006) Excess Mortality related to the August 2003 Heat Wave in France. Int Arch Occup Environ Health 80:16-24. doi:10.1007/s00420-006-0089-4 
Frota A, Schiffer S (1987) Manual de Conforto Térmico, 5th edn. Studio Nobel, São Paulo

Garssen J, Harmsen C, De Beer J (2005) The effect of the summer 2003 heat wave on mortality in the Netherlands. Euro Surveill 10(7), http://www.eurosurveillance.org/ViewArticle.aspx?ArticleId=554

Gosling SN, McGregor GR, Lowe JA (2009) Climate change and heatrelated mortality in six cities. Part 2: climate model evaluation and projected impacts from changes in the mean and variability of temperature with climate change. Int J Biometeorol 53:31-51, doi: 10.1007/s00484-008-0189-9

Grize L, Hussa A, Thommena O, Schindlera C, Braun-Fahrländera C (2005) Heat wave 2003 and mortality in Switzerland. Swiss Med Wkly 135:200-205

Hajat S, Kovats R, Atkinson R, Haines A (2002) Impact of hot temperatures on death in London: a time series approach. J Epidemiol Commun Health 56:367-372. doi:10.1136/jech.56.5.367

Hajat S, Armstrong B, Bacini M, Biggeri A, Bisanti L, Russo A et al (2006) Impact of high temperature on mortality: is there an added heat wave effect? Epidemiology 17:632-638

Hertel S, Tertre A, Jockel K, Hoffmann B (2009) Quantification of the Heat Wave effect on cause-specific Mortality in Essen, Germany. Eur J Epidemiol 24:407-414. doi:10.1007/s10654-009-9359-2

Huang W, Kan H, Kovats S (2010) The impact of the 2003 heat wave on mortality in Shanghai, China. Sci Total Environ 408:24182420

Hutter P, Moshammer H, Wallner P, Leitner B, Kundi M (2007) Heatwaves in Vienna: effects on mortality. Wien Klin Wochenschr 119(7-8):223-227. doi:10.1007/s00508-006-0742-7

Huynen M, Martens P, Schram D, Weijenberg M, Kunst A (2001) The impact of heat waves and cold spells on mortality rates in the Dutch population. Environ Health Perspect 109(5):463-470

Jendritzky G (1993) Human biometeorology part I. Experientia 499:733-740

Johnson H, Kovats S, McGregor G et al (2005) The impact of the 2003 Heat Wave on daily mortality in England and Wales and the use of rapid weekly mortality estimates. Euro Surveill 10(7), http:// www.eurosurveillance.org/ViewArticle.aspx?ArticleId $=558$

Keatinge W, Coleshaw S, Easton J, Cotter F, Mattock M, Chelliah R (1986) Increased platelet and red cell counts, blood viscosity, and plasma cholesterol levels during heat stress, and mortality from coronary and cerebral thrombosis. Am J Med 81:795-800

Kenney W (1997) Thermoregulation at rest and during exercise in healthy older adults. Exercise Sport Sci R 25:41-76

Kilbourne E (1999) The spectrum of illness during Heat Waves. Am J Prev Med 16(4):359-360

Klinenberg E (2002) Heat Wave: a social autopsy of disaster in Chicago. Chicago: University of Chicago Press, 305 pp. ISBN 0-22644321-3

Koppe C, Jendritzky G, Kovats R, Menne B (2003) Heatwaves: impacts and responses. World Health Organization, Copenhagen

Kovats R, Ebi K (2006) Heatwaves and public health in Europe. Eur J Public Health 16(6):592-599. doi:10.1093/eurpub/ck1049

Kyselý J (2004) Mortality and displaced mortality during Heat Waves in the Czech Republic. Int J Biometeorol 49:91-97. doi:10.1007/ s00484-004-0218-2

Liang WM, Liu WP, Chou SY, Kuo HW (2008) Ambient temperature and emergency room admissions for acute coronary syndrome in Taiwan. Int J Biometeorol 52:223-229

Linares D, Díaz J (2007) Impact of high Temperatures on hospital admissions: comparative analysis with previous studies about mortality (Madrid). Eur J Public Health 18(3):317-322. doi:10.1093/eurpub/ckm108

Mastrangelo G, Fedeli U, Visentin C, Milan G, Fadda E, Spolaore P (2007) Pattern and determinants of hospitalization during Heat Waves: an ecologic study. BMC Public Health 7:200. doi:10.1186/ $1471-2458-7-200$
McGeehin M, Mirabelli M (2001) The potential impacts of climate variability and change on temperature related morbidity and mortality in the United States. Environ Health Perspect 109(Suppl 2): $185-189$

Meehl G, Tebaldi C (2004) More intense, more frequent, and longer lasting Heat Waves in the 21st century. Science 305:994-997. doi:10.1126/science.1098704

Michelozzi P, Sario M, Acetta G, Donato F, Kirchmayer U, Ovidio M, Perucci C (2006) Temperature and summer mortality: geographical and temporal variations in four Italian cities. J Epidemiol Community Health 60:417-423. doi:10.1136/jech.2005.040857

Michelozzi P et al (2009) High temperature and hospitalizations for cardiovascular and respiratory causes in 12 European cities. Am J Respir Crit Care Med 179:383-389

National Institute of Statistics (2001) General population and northern region's housing census. Available from http://www.ine.pt (Accessed 1 April 2011)

National Weather Service Weather Forecast Office (Accessed April 2011) Summer Weather Safety and Survival. Heat Index. Available from http://www.weather.gov/ (Accessed 10 February 2011)

Naughton M, Henderson A, Mirabelli M, Kaiser R, Wilhelm J, Kieszak S, Rubin C, McGeehin M (2002) Heat-related mortality during a 1999 Heat Wave in Chicago. Am J Prev Med 22(4):221-227

Nogueira P, Falcao J, Contreiras M et al (2005) Mortality in Portugal associated with the Heat Wave of August 2003: early estimation of effect, using a rapid method. Euro Surveill 10(7):150-153 http://www.eurosurveillance.org/ViewArticle.aspx?ArticleId=553 (Accessed 15 October 2011)

Pirard P, Vandentorren S, Pascal M, Laaidi K, Le Tertre A, Cassadou S, Ledrans M (2005) Summary of the Mortality impact assessment of the 2003 Heat Wave in France. Euro Surveill 10(7) Available online: http://www.eurosurveillance.org/ViewArticle.aspx? ArticleId $=554$ (Accessed 13 February 2011)

Planton S, Déqué M, Chauvin F, Terray L (2008) Expected impacts of climate change on extreme climate events. C R Geosci 340:564574. doi:10.1016/j.crte.2008.07.009

Rey G, Jougla E, Fouillet A, Pavillon G, Bessemoulin P, Fraussinet P, Clavel J, Hémon D (2007) The impact of major hear waves on allcause and cause-specific mortality in France from 1971 to 2003. Int Arch Occup Environ Health 80:615-626. doi:10.1007/s00420007-0173-4

Rooke G, Savage M, Brengelmann G (1994) Maximal skin blood flow is decreased in elderly men. J Appl Physiol 77:11-14

Rooney C, McMichael A, Kovats R, Coleman M (1998) Excess Mortality in England and Wales, and in Greater London, during the 1995 heatwave. J Epidemiol Community Health 482(52):482486

Rothfusz L (1990) The heat index "equation." National Weather Service Technical Attachment (SR 90-23)

Saez M, Sunyer J, Castellsagué J, Murillo C, Antó J (1995) Relationship between weather temperature and mortality: a time series analysis approach in Barcelona. Int J Epidemiol 24:576-582

Schiffano P, Cappai G, Sario M, Michelozzi P, Marino C, Bargagli A, Peruci C (2009) Susceptibility to Heat Wave-related mortality: a follow-up study of a cohort of elderly in Rome. Environ Health 8:50. doi:10.1186/1476-069X-8-50

Schulman S, Lakatta E, Fleg J, Lakatta L, Becker L, Gerstenblith G (1992) Age related decline in left ventricular filling at rest and exercise. Am J Physiol 263:1932-1938

Semenza J, Carol M, Rubin H, Kenneth M, Falter H, Selanikio J, Flanders D, Howe H, Wilhelm J (1996) Heat-related deaths during the July 1995 Heat Wave in Chicago. New Engl J Med 335 (2):84-90

Semenza J, McCullough J, Flanders W, McGeehin M, Lumpkin J (1999) Excess hospital admissions during the July 1995 Heat Wave in Chicago. Am J Prev Med 16(4):269-277 
Simon F, Lopez-Abente G, Ballester E, Martinez F (2005) Mortality in Spain during the Heat Waves of summer 2003. Euro Surveill 10(7). Available online: http://www.eurosurveillance.org/ViewArticle.aspx? ArticleId $=555$

Steadman R (1979a) The assessment of sultriness. Part I: A temperature-humidity index based on human physiology and clothing science. J Appl Meteorol 18(7):861-873

Steadman R (1979b) The assessment of sultriness. Part II: Effect of wind, extra radiation, and barometric pressure on Apparent Temperature. J Appl Meteorol 18(7):874-884

Steadman R (1984) A Universal Scale of Apparent Temperature. J Clim Appl Meteorol 23(12):1674-1687

Stedman J (2004) The predicted number of Air Pollution related deaths in the UK during the August 2003 heatwave. Atmos Environ $38: 1087-1090$
Tan J, Zheng Y, Song G, Kalkstein L, Kalkstein J, Tang X (2007) Heat Wave impacts on Mortality in Shanghai, 1998 and 2003. Int J Biometeorol 51:193-200. doi:10.1007/s00484006-0058-3

Tan J, Zheng Y, Tang X, Guo C, Li L, Song G, Zhen X, Yuan D , Kalkstei A, Li F, Chen H (2010)The urban heat island and its impact on Heat Waves and human health in Shanghai. Int J Biometeorol 54:75-84doi: 10.1007/s00484-009-0256-X

Weisskopf M, Anderson H, Foldy S, Hanrahan L, Blair K, Török T, Rumm P (2002) Heat Wave morbidity and mortality, Milwaukee, Wis, 1999 vs 1995: an improved response? Am J Publ Health Res Pract 92(5):830-833

Whitman S, Good G, Donoghue E, Benbow N, Shou W, Mou S (1997) Mortality in Chicago attributed to the July 1995 Heat Wave. Am J Public Health 87(9):1515-1518 